mula) for months together, for inflammation of the eyes; the eyes have certainly benefited by the treatment, but I should be glad to learn what is the specific remedy for prolapsus ani, ulcerated bowels, rickets, \&c. \&c.

I might also extend the length of this communication by noticing other diseases of the larynx occurring in young and old; I shall merely observe now, that in all cases of aphonia and dysphonia we should expect danger, and generally prescribe protecting doses of calomel, or other forms of mercury, confining the patient to his room, and that we shculd never think too lightly of the thrush in infunts, as $I$ have met with several cases in which the disease has proved almost suddenly fatal by attacking the upper part of the larynx.

Finally, I beg leave to express a hope that in recommending such unusual doses I shall not incur the precipitate censure of those who have never tried them, and who may be less painfully acquainted with the fatality of croup than myself; fiom their present condemnation I would appeal to the judgment of experience. To those who have in vain contended with this often indomitable disease, I would earnestly recommend the practice, however they may disapprove of the theory. If from experiment or experience some happier method be devised, I shall feel grateful for its communication through the same medium in which these observations appear, if convinced of error, I have the satisfaction of believing that no one would submit more willingly to be corrected than

Your obedient humble servant, Henhy ReEs.

45, Finsbury Square, Dec., 1831.

SUCCESSFUL EMPLOYMENT OF THE

\section{HYDRIODATE OF POTASH IN}

\section{PHTHISIS PULMONALIS ?}

\section{To the Editor of The Laxcer.}

Sir,-Having unitormly observed that your pages are not only open to the communications of the more matured, but receive also with equal frankness the contributions even of the humblest members of the profession, I, though a mere student, am emboldoned to lay betore your readers the following case, which, on account of the novel treatment adopted, and the satisfactory result, I have thought, may not be unacceptable.

I am, Sir, your obedient servant,

5, Trin. Coll. Dublin,

EDMund Sha RKEY, A.B.

Nov, 28, 1831 .
CASE.

Julia Doyle, xt. 11, of the complexion and cast of features usually set down as in. dicative of the strumous diathesis, some years ago had scarlatina, with pectoral symptoms, followed by intermittent fever. Since that time her chest has never been bealthy ; has had a cough these three years, aggravated within the last few weeks, and accompanied by loss of appetite, depression and emaciation to a certain extent.

I saw her on Dec. 1st, 1830, when her state was as follows:-cough severe, pre* ventiug sleep; expectoration copious, principally during night; pulse 120 ; tongue clean; bowels regular; has distinct rigors towards evening. Physical stgns-chest on percussion clear, except over ight sch= pula, where there is a de re ef dulness, accompanied by feeble respiratory murmur; slightresonance of the voice, and action of the heart distinctly audible. A "click," perhaps a bubble or two of mucous rale, is also occasionally heard during inspiration; respiration puerile over left scapula. Con. sidering the foregoing symptoms as indicating a tubercular deposition at top of right lung, I determined to treat it as such; but, tired of witnessing the usual routine of practice and its universal failure, I resolved on trying, if possible, something new, and having seen some surprising instances of the efficacy of ung. hydriod. potasse in promoting absorption of extraneous productions apparently beyond the reach of the absorbents, I determined to use it in this case, but I allow with very feeble hopes of success. In order to fulfil therefore the several in. dications, viz., allaying the irritation caused by the presence of tubercles, promoting their absorption, correcting the diathesis which gave rise to them, and supporting the strength, Iordered flannel next the skin, light nutritious diet, exercise, as far as consistent with avoiding too great exposure to atmospheric changes, and prescribed mist. mucil.c. tinct. op. camph.; friction of un. guent. hydriod. potassa about the size of a nut, twice a day over right scapula; and a half wine-glass of aqua calcis three times a day. The report of the 11 th stands thus; con. siderable general improvement; cough de. minished, countenance more lively; appe. tite better; rigors less frequent; pulse 76. Pergat.

21. Improvement continues; rigors altogether gone ; pulse 76 .

Feb. 12, 1831. Ilas continued to improve since last report in spite of very severe weather. On examination by percussion and the stethoscope, it appears that the dulness over right scapula, and resonanco of roice in same situation, have disappeared, and there is no perceptible difference in the strength of respiration as compared in 
both sides in this situation. No râle audiable in chest.

Nov. 25, 1851. I saw the girl a day or two since, and she has continued free from all ailment, and has acquired quite a healthy appearance. I am aware of the great difficulty of unequivocally ascertaining the existence of incipient phithisis, and of the numerous objections which have always been urged against alleged cases of phthisis cured; but l cannot help thinking, upon a review of the whole case, that it was one of that nature. First, as to the fact of dulness at the apex of right lung and feeble respiration, I have no doubt about it, as I examined repeatedly and carefully and (after the rapid amendment taking place) with great distrust, and thoroughly convinced myself, almost with reluctance, conscious of the truth " quod volumus facile credimus ;" secondly, this dulness, it is true, might have arisen from several causes beside the one assigned by me; for instance pneumonia, peculiar conformation, extensive pleuritic adhesions, copious secretion of viscid inspissated mucus in the large bronchial tubes. The history of the case and th 3 ...ature of the expectoration (which was always thin) forbid the first and last supposition, and the subsequent disappearance of those phenomena are irreconcilable with the other two. I may add, in corroboration, that in the summer preceding, the patient's sister was examined by an eminent physician and accomplished stethoscopist (Dr. William Stokes), pronounced to have a cavity under the right clavicle, and after wards died with all the symptoms of exquisite phthisis.

I must acknowledge that $I$ have tried this treatment in several cases since, but without any permanent good effect, except in one case, very ebronic, occurring in a boy long affected with various scrofulous complaints, and presenting all the phenomena of a large $\mathrm{e}$ cavity in top of left lung, with those of great hypertiophy of the heart, but in this case I am doubtful how far the amendment was attributable to chlorine in halation, which I used in conjunction; however, the unsuccessful cases were all farther advanced, and, occurring, as they did, among the poorest class, were precluded from the advantage of the other powerful adjuvants, good diet, pure air, \&c., which were enjoy. ed by the two successful ones, who were of the better order. It may perhaps be said, that I should not have put forward a mode of treatment based on so limited an extent of success. But rather than defer, till the probably distant period of ample observation, a suggestion which could possibly be of use in such a hopeless disease, I have preferred presenting to the profession the result even of my meagre experience, and

No. 443 . shall cheerfully submit to any change of precipitancy, if a more extensive trial under the favourable circumstances of cases in private practice, shall be the means of rescuing even one in a thousand of the count'ess multitudes who are sacrificed by a malady, whose ravages are the more deplorable as it almost uniformly selects its victims from among the loveliest and most amiable specimens of our race.

\section{THE CHOLERA.}

\section{CASES OF CHOLERA IN THE BOROUGH.}

\section{To the Editor of $\mathrm{T}_{\mathrm{n}} \mathrm{L}$ Lancet.}

Sr $\mathrm{R},-\mathrm{I}$ beg to forward for your inspection the following rough notes of some cases of cholera which have occurred this week in the Borough, and which came more particularly under my care. They were patients of Mr. Clarke, the parish surgeon, and have been repertedly seen by that gentleman, Mr. Seurle, Mr. Howship, \&c

Case 1.-Hannañ Daly, residing in Hammer Alley, a strong, healthy, woman, aged 28, was attacked on Sunday, the 12th inst., with diarrhoa, which continued, more or less, until the following Tuesday. She had been out during the morning, and on hes return was seized wich violent spasms of the abdomen and lower extremities, vomiting, purging, \&c. Medical aid was called in, and she was bled to the amount of six ounces, and the hot-air bath was malle use of for some time. There was great pros. tration, and the pulse was scarcely perceptible. The blood was obtained with much difficulty, was very dark, and soon coagulated. 'I'his had been obtained before [ visited her.

At two P.M. I first saw the woman, when she presented the prominent symptoms of spasmodic cholera. The blue appearance of the face, hands, \&c.; violent spasms, distressing vomiting, pulse imperceptible at the wrist, purging of a thin, colourless fluid, pan in the epigastic region, \&c. The bleeding did not appear to have done much good. Mr. Searle now saw the patient, pronounced it to be a case of spasmodic cholera, and strongly advised the exhibition of large doses of calomel at regular intervals, together with the use of enemata composed of warm water and common salt (in the proportion of a pint of the former to a table-spoonful of the latter) every half hour. I now took charge of the case, and agreeably to Mr. Serrle's directions, gave her a scruple of calomel immediately, and threw up an injection. In half an hour I repeated it, and at three o'clock 